\title{
Transference patterns in the psychotherapy of personality disorders: empirical investigation
}

\author{
REBEKAH BR ADLEY, AMY KEGLEY HEIM and DREW WESTEN
}

\author{
Background The concept of \\ transference has broadened to a \\ recognition that patients often express \\ enduring relational patterns in the \\ therapeutic relationship.
}

\begin{abstract}
Aims To examine the structure of patient relational patterns in psychotherapy and their relation with DSM-IV personality disorder symptoms.
\end{abstract}

\begin{abstract}
Method A random sample of psychologists and psychiatrists $(n=|8|)$ completed a battery of instruments on a randomly selected patient in their care.
\end{abstract}

Results Exploratory factor analysis identified five transference dimensions: angry/entitled, anxious/preoccupied, avoidant/counterdependent, secure/ engaged and sexualised. These were associated in predictable ways with Axis II pathology; four mapped on to adult attachment styles. An aggregated portrait of transference patterns in narcissistic patients provided a clinically rich, empirically based description of transference processes that strongly resembled clinical theories.

\section{Conclusions The ways patients interact with their therapists can provide important data about their personality, attachment patterns and interpersonal functioning. These processes can be measured in clinically sophisticated and psychometrically sound ways. Such processes are relatively independent of clinicians' theoretical orientation.}

Declaration of interest None. Funding detailed in Acknowledgements.
Since Freud's initial recognition that patients may enact interpersonal patterns in the therapy relationship (Freud, 1912, 1917), the concept of transference has evolved considerably (Sandler, 1976; Wachtel, 1997). In contemporary terms, transference refers broadly to patterns of thought, feeling, motivation and behaviour that emerge in the therapeutic relationship and reflect enduring aspects of the patient's personality and interpersonal functioning (Westen \& Gabbard, 2002). Although a small body of research exists on transference processes (e.g. Luborsky \& CritsChristoph, 1990; Curtis et al, 1994), much of our understanding of transference is derived from clinical observation. In this study we applied a clinician-report measure of transference phenomena to a sample of patients in psychotherapy, with two goals: first, to identify the structure of patients' relational patterns as observed in psychotherapy; and second, to test hypotheses about the relation between transference patterns and personality pathology. The broader goal of this research was to develop a clinically sophisticated, psychometrically sound measure of patients' interaction patterns in psychotherapy (including thoughts, feelings, affect regulation strategies, motives, behaviours and conflicts) that could be useful in research and practice.

\section{METHOD}

We used a practice network approach, in which randomly selected clinicians provide data on patients that can be aggregated across large samples (Westen \& Shedler, 1999; Margison et al 2000; Audin et al, 2001; Shelder \& Westen, 2004). Elsewhere we have addressed in detail the rationale for clinician-report data, including advantages and limitations (see Westen \& Weinberger, 2004). The primary advantage is that clinicians are experienced observers, with skills and a normative basis with which to make inferences and recognise nuances in psychopathology. The primary objection is the possibility of bias in clinical judgement. Recent research suggests, however, that clinicians tend to make highly reliable and valid judgements if their observations are quantified using psychometric instruments. Correlations between treating clinicians' and independent interviewers' assessments of a range of clinical variables on instruments designed for use by experienced clinicians tend to be large, typically over 0.50 (Hilsenroth et al, 2000; Westen \& Muderrisoglu, 2003), and clinician-reported personality data predict measures of adaptive functioning, attachment patterns, and family and developmental history suggestive of validity (Nakash-Eisikovits et al, 2002; Westen et al, 2003). Clinician theoretical orientation predicts little variance in descriptions of clinical phenomena when clinicians are asked to describe a specific patient rather than their beliefs or theories (Shedler \& Westen, 2004).

\section{Participants}

Participants were 181 experienced clinicians randomly selected from the membership registers of the American Psychiatric and American Psychological Associations. We requested mailing lists of clinicians with at least 3 years' post-licensure or postresidency experience, who indicated that they performed at least 10 hours per week of direct patient care. Approximately 10\% of solicited clinicians returned postcards indicating their interest in participating in a project requiring approximately $4 \mathrm{~h}$ of their time for an honorarium of US $\$ 85$. Validity checks comparing psychologists with psychiatrists, who responded at substantially different rates, uncovered no significant difference on any variable of interest (13 $t$ tests and analyses of variance, $P<0.01$ ), suggesting that the relatively modest response rate (reflecting substantial time commitment for a token honorarium) was unlikely to account for the findings (see Limitations).

\section{Inclusion and exclusion criteria}

To obtain a cross-section of psychotherapy patients seen in clinical practice, we asked clinicians to describe a non-psychotic patient at least 18 years old who they had treated with psychotherapy for a minimum of eight sessions (to maximise the likelihood that they would know the patient well 
enough to provide a reasonably accurate description) and for a maximum of 2 years (to avoid confounds associated with substantial personality changes with treatment). To minimise selection biases, we directed clinicians to select the last patient they saw during the prior week who met study criteria. Each clinician described only one patient, to minimise rater-dependent biases. We stratified the sample to ensure equal numbers of men and women.

\section{Procedure}

Clinicians could participate either by pen and paper or on an interactive website (http://www.psychsystems.Net). Clinicians provided no identifying information about the patient and were instructed to use only information already available to them from their contact with the patient, so that data collection would not compromise confidentiality or interfere with ongoing clinical work.

\section{Measures}

Clinicians completed a large battery of measures. Those relevant to this study are described below (more details are given by Russ et al, 2003, and at http://www. psychsystems.Net).

\section{Clinical Data Form}

The Clinical Data Form (CDF) (Westen \& Shedler, 1999) assesses a range of variables relevant to demographics, diagnosis and aetiology. Clinicians provide basic demographic data about themselves, including discipline (psychiatry or psychology), theoretical orientation, employment sites (e.g. private practice, in-patient unit, school) and gender; the patient, including age, gender, ethnicity, education level, socioeconomic status and Axis I diagnoses. Following basic demographic and diagnostic questions, clinicians rate the patient's adaptive functioning and a range of aetiological variables (developmental and family history of psychiatric disorders). Several studies have supported the validity of CDF variables, such as adaptive functioning, developmental history and clinician-reported theoretical orientation (Westen et al, 2003; Thompson-Brenner \& Westen, 2005).

\section{Psychotherapy Relationship Questionnaire}

The Psychotherapy Relationship Questionnaire (PRQ; Westen, 2000) is a 90 -item clinician-report questionnaire designed to provide a normed, psychometrically valid instrument for assessing transference patterns in psychotherapy for both clinical and research purposes. The items measure a wide range of thoughts, feelings, motives, conflicts and behaviours expressed by patients toward their therapist that have traditionally been described as both 'transference' and 'working alliance'. We derived the 90 items of the PRQ by reviewing the clinical, theoretical and empirical literature on transference, therapeutic/ working alliance and related constructs, and soliciting the advice of several experienced clinicians to review the initial item set for comprehensiveness and clarity. We wrote the items in everyday language, without jargon, so that the instrument could be used equally well by clinicians of any theoretical orientation. For example, to capture Kohut's concept of 'mirror' and 'twinships' transference in patients with narcissistic disorders (Kohut, 1968), we included items such as 'Assumes that the therapist shares his/her point of view, beliefs, values, etc., even where this is unlikely' and 'Imagines $\mathrm{s} / \mathrm{he}$ and the therapist are much more similar than they really are; seems to want to be "twins" with the therapist' (a copy of the measure can be obtained at http:// www.psychsystems.Net).

\section{Axis II diagnosis}

To assess Axis II disorders, we asked clinicians to rate as present or absent each criterion of each of the DSM-IV Axis II disorders, randomly ordered (American Psychiatric Association, 1994). This provides both a categorical diagnosis for each disorder (obtained by applying diagnostic cut-offs) and a dimensional measure (number of criteria met for each disorder).

\section{RESULTS}

\section{Sample characteristics}

The clinician sample included $78 \%$ psychologists and $22 \%$ psychiatrists. The most commonly self-reported theoretical orientations included psychodynamic $(40 \%)$, eclectic $(30 \%)$ and cognitive-behavioural $(20 \%)$. Patients $193 \%$ of whom were White) had an average age of 40.5 years (s.d.=13.4); half $(51 \%)$ were female. The mean Global Assessment of Functioning (GAF; American Psychiatric Association, 1987) score was 58.0 (s.d.=12.9). Most patients were middle-class $(56 \%)$, whereas
$27.1 \%$ were described as poor or workingclass and $17 \%$ as upper-class; $68 \%$ had completed college or higher levels of education. Length of treatment averaged 19 months (s.d. $=30.0$, median 13), indicating that the clinicians knew the patients very well. The most common Axis I diagnoses reported by clinicians were major depressive disorder $(40 \%)$, dysthymic disorder $(38 \%)$, generalised anxiety disorder $(26 \%)$ and adjustment disorder $(25 \%)$.

\section{Factor structure of the PRQ}

As a first step in identifying the factor structure of the PRQ, we subjected the items to a principal components analysis using Kaiser's criteria (eigenvalues $>1$ ). We used the scree plot, percentage of variance accounted for and parallel analysis (Horn, 1965; O'Connor, 2000) to select the number of factors to rotate. The scree plot indicated a break between five and six factors, and parallel analysis indicated that five factors had eigenvalues larger than would be expected by chance. Several factors emerged across algorithms and rotations, with the most coherent solution emerging from a five-factor oblique (Pro$\max )$ solution which accounted for $45 \%$ of the variance (with factors each accounting for $2.5 \%$ to $26.4 \%$ of the variance); further details are available from the authors upon request.

Table 1 describes the factors. To create factor-based (unit weighted) scores, we included items loading 0.50 or more for factor 1 and 0.40 or more for factors 2-5 to maximise reliability. Intercorrelations among the five factors ranged from -0.12 to 0.54 , with a median of 0.14 .

\section{Factor I}

Factor 1, angry/entitled (coefficient $\alpha=0.94$ ), is marked by items indicating a tendency to make excessive demands of the therapist while simultaneously being angry and dismissive. The items accord with clinical descriptions of transference processes in patients with Axis II cluster B disorders, notably narcissistic and borderline personality disorders.

\section{Factor 2}

Factor 2, anxious/preoccupied (coefficient $\alpha=0.85$ ), includes items describing fear of the therapist's disapproval, fears of rejection by the therapist, an overly compliant and dependent attitude toward the 
Table I Factor structure of the Psychotherapy Relationship Questionnaire $(n=|8|)$

\begin{tabular}{llll}
\hline Factor & 3 & 2 \\
\hline
\end{tabular}

Factor I: Angry/entitled

Behaves in ways that seem entitled (e.g. wants special favours, a lower fee than is warranted by his/her income) 0.85

Vacillates between idealising and devaluing the therapist 0.84

Feels critical of the therapist 0.71

Repeatedly tests or fails to respect the boundaries of the therapeutic relationship 0.69

Is argumentative $\quad 0.69$

Is provocative; tends to set up situations in which the therapist feels angry, attacked or provoked 0.69

Is oppositional; tends to disagree with the therapist's approach, comments, suggestions, etc. 0.69

Plays the therapist off against another person (e.g. a parent, spouse or other therapist) 0.68

Is manipulative 0.67

Needs to be special to the therapist; wants to be more important than the therapist's other patients 0.67

Flies into rages at the therapist 0.67

Requires or demands excessive contact, love, etc., from the therapist 0.66

Is sadistic toward the therapist (e.g. enjoys making the therapist squirm) 0.64

Feels angry toward the therapist 0.64

Needs excessive admiration from the therapist 0.60

Imagines s/he and the therapist are much more similar than they really are; seems to want to be 'twins'

with the therapist

Voices concerns that the therapist is not doing enough to help 0.57

Is dismissive or devaluing toward the therapist 0.54

Is competitive with the therapist 0.52

Elicits sadism, sarcasm or other subtle or overt aggressive responses from the therapist 0.52

Is prickly; makes the therapist feel as if s/he is 'walking on eggshells' $0.5 \mathrm{I}$

Expresses wish that the therapist could be his/her parent 0.51

Vacillates between considerable involvement/investment in the therapy and thoughts of quitting 0.50

Tries to get the therapist to take his or her side in conflicts with other people 0.50

Factor 2: Anxious/preoccupied

Feels, or fears, doing 'something wrong' in therapy 0.79

Feels inferior to the therapist

Is afraid of contradicting or disagreeing with the therapist; has trouble asserting own needs or viewpoint

Fears $s /$ he is failing the therapist

Has trouble talking about own successes, achievements or pride with the therapist

Is overly compliant

Is afraid of being abandoned by the therapist

Is afraid to speak his/her mind, for fear of provoking attack, dislike, etc., from the therapist

Appears comfortable in a child-like role in therapy; tends to draw parent-like responses from the therapist

Feels deeply ashamed about his/her actions, wishes, symptoms, fantasies, etc.

Has difficulty expressing anger or disappointment toward the therapist, even when the therapist has made

a mistake or not been helpful

Is uncomfortable imagining that the therapist cares about him/her, despite obvious indications otherwise

Worries that the therapist does not like him/her

Pulls for the therapist to be directive, wants the therapist to tell him/her what to do

Factor 3: Secure/engaged

Elicits warm feelings from the therapist 


\begin{tabular}{|c|c|c|c|c|c|}
\hline Factor & $\mathbf{I}$ & 2 & 3 & 4 & 5 \\
\hline \multicolumn{6}{|l|}{ Factor 3: Secure/engaged (continued) } \\
\hline Talks openly and self-reflectively about the therapy relationship & & & 0.56 & & \\
\hline Works hard in therapy & & & 0.53 & & \\
\hline Is indifferent to the therapist; expresses little feeling towards the therapist, either overtly or covertly & & & -0.51 & & \\
\hline Is able to talk openly about difficult material & & & 0.51 & & \\
\hline Feels fond of or loving towards the therapist & & & 0.51 & & \\
\hline Is passive; seems to expect the therapist to do all the work & & & -0.49 & & \\
\hline Feels nurtured by the therapist & & & 0.47 & & \\
\hline Feels protective of the therapist; worries about hurting him/her & & & 0.44 & & \\
\hline Is help-rejecting; seems to rebuff earnest efforts by the therapist to be helpful & 0.36 & & & & \\
\hline Is off-putting & 0.32 & & -0.43 & & \\
\hline Feels helped by the therapist & & & 0.42 & -0.32 & \\
\hline \multicolumn{6}{|l|}{ Factor 4: Avoidant/counterdependent } \\
\hline Tries hard not to be, or feel, needy or dependent in therapy & & & & 0.74 & \\
\hline Is uncomfortable not feeling 'in control' in therapy & & & & 0.65 & \\
\hline Is uncomfortable feeling taken care of; experiences getting help as a failure, a loss of independence, etc. & & 0.36 & & 0.64 & \\
\hline Is afraid to open up and be vulnerable for fear of being or appearing weak, dependent, etc. & & 0.36 & & 0.57 & \\
\hline Has difficulty committing to therapy; always seems to have 'one foot out the door' & & & & 0.49 & \\
\hline Seems to maintain distance from the therapist; tries to keep the therapist at arm's length & & & -0.40 & 0.46 & \\
\hline Denies that the therapist means anything to him/her, despite obvious evidence to the contrary & & & & 0.45 & \\
\hline \multicolumn{6}{|l|}{ Factor 5. Sexualised } \\
\hline Is sexually attracted to the therapist & & & & & 0.90 \\
\hline Tries hard not to feel, or admit feeling, sexually attracted to the therapist & & & & & 0.81 \\
\hline Wishes the therapist could be his/her spouse or lover & & & & & 0.76 \\
\hline Is afraid of his/her attraction to the therapist & & & & 0.32 & 0.67 \\
\hline Is sexually seductive or flirtatious with the therapist & & & & & 0.64 \\
\hline Is overly interested in, or concerned about, the therapist's relationship with other patients & 0.38 & & & & 0.41 \\
\hline
\end{tabular}

therapist, and a wish for the therapist to solve problems or 'take care' of the patient. This factor describes a style of relating to the therapist that strongly resembles the adult attachment style labelled 'preoccupied', which is related to the childhood classification of anxious/ambivalent attachment (Main et al, 1985).

\section{Factor 3}

Factor 3, secure/engaged (coefficient $\alpha=0.86$ ), is marked by items describing the patient's contribution to a positive working alliance and a playful, comfortable, secure experience of the therapy relationship.

\section{Factor 4}

Factor 4, avoidant/counterdependent (coefficient $\alpha=0.84$ ), is marked by items describing efforts to avoid meaningful connection with or dependence on the therapist. It appears conceptually related to both the dismissing (avoidant) adult attachment style and to dynamics common in obsessional and socially withdrawn patients.

\section{Factor 5}

Factor 5, sexualised (coefficient $\alpha=0.86$ ), is marked by items describing sexual feeling towards the therapist, including a tendency to act in a seductive manner.

\section{Ruling out theoretical bias}

The factor structure described above is conceptually coherent; nevertheless, an important question is the extent to which its coherence reflects the nature of the patients described in the sample or the theoretical beliefs of participating clinicians, particularly given that nearly half shared a theoretical orientation that has emphasised transference phenomena (psychodynamic).
To evaluate this possibility, we conducted a second factor analysis using the same procedures, this time eliminating all clinicians who reported a psychoanalytic or psychodynamic orientation (remaining $n=120$ ). (Confirmatory factor analysis was inappropriate, because these were a subsample of the original sample.) The second factor analysis yielded factors virtually identical to the first four factors of the original factor analysis, with a median correlation between the two versions of each factor of $r=0.96$. The primary difference between the second factor solution and the solution using the entire sample was that several items from the sexualisation factor loaded on the secure/engaged factor instead of constituting a separate factor, probably because of the smaller sample size. Thus, the factor structure does not appear to be an artefact of clinicians' theoretical preconceptions. Indeed, the first four factors seem to map on to the disorganised/ 
unresolved, secure, avoidant/dismissing and anxious/preoccupied attachment patterns described in the developmental literature, with which most clinicians are relatively unfamiliar (and which we did not anticipate).

\section{Transference and personality pathology}

As a first test of the validity and clinical applicability of the PRQ, we examined the relationship between each of the five factors and dimensional measures of the DSM-IV personality disorders. Because of the extensive comorbidity of the Axis II disorders, we analysed the data at the cluster level (clusters A, B and C) by summing the number of symptoms endorsed for each All three clusters were represented in the sample: $15.5 \%$ met criteria for a cluster A disorder, $28.2 \%$ for cluster $\mathrm{B}$ and $38.7 \%$ for cluster C. To control for comorbidity across clusters (and for general severity of personality disturbance), we partialled out the other two clusters in all analyses.

Based on the item content of the factors, we made three a priori predictions: that the cluster A (odd/eccentric) disorders would be associated with the avoidant/ counterdependent factor; that the cluster B (dramatic/erratic) disorders would be associated with the angry/entitled and sexualised factors; and that the cluster $\mathrm{C}$ disorders (anxious/fearful) would be associated with anxious/preoccupied transference. The second and third hypotheses were strongly supported by the data (Table 2). Findings were weaker for the first of these hypotheses, which showed a trend toward significance $(P=0.08)$. In addition, the cluster $\mathrm{A}$ (odd/eccentric) disorders showed a negative correlation with secure/engaged. of the disorders constituting each cluster.

To illustrate the clinical uses of the instrument, and to examine the extent to which it can be used to create empirical prototypes of common transference patterns in specific types of disorder, we created a composite description of the transference patterns of patients in the sample who met DSM-IV criteria for narcissistic personality disorder. (We chose the latter disorder because we wanted to bring to bear empirical methods on a disorder that has generated substantial clinical theory, particularly with respect to transference, but relatively little research.) We standardised the items across patients and then averaged the item scores of patients meeting DSM-IV criteria for narcissistic personality disorder from the Axis II checklist. By standardising items (setting means to 0 ) before aggregating, we reduced the salience of items descriptive of all patients in the sample (narcissists included) but not specific to narcissistic personality disorder. Table 3 presents the items most and least descriptive of therapist descriptions of transference processes in patients with narcissistic personality disorder $(n=13)$. The composite description is remarkably similar to theoretical accounts of narcissistic transferences (e.g. Kohut, 1968; Kernberg, 1975). Interestingly, the composite excluding clinicians reporting a psychodynamic orientation was virtually identical, once again suggesting that the findings do not reflect clinicians' biases or expectations.

\section{DISCUSSION}

We identified five transference dimensions that were robust across extraction methods and rotations: angry/entitled, anxious/ preoccupied, secure/engaged, avoidant/ counterdependent and sexualised. These dimensions are clinically and theoretically coherent, representing different ways in which patients interact with their therapists

Table 2 Partial correlations between patient interaction factors and Axis II cluster $(n=|8|)$

\begin{tabular}{lllccc}
\hline & $\begin{array}{c}\text { Angry/ } \\
\text { entitled }\end{array}$ & $\begin{array}{c}\text { Anxious/ } \\
\text { preoccupied }\end{array}$ & $\begin{array}{c}\text { Secure/ } \\
\text { engaged }\end{array}$ & $\begin{array}{c}\text { Avoidant/ } \\
\text { counterdependent }\end{array}$ & Sexualised \\
\hline Cluster $\mathrm{A}^{\prime}$ & 0.04 & 0.01 & $-0.20^{* *}$ & 0.10 & -0.11 \\
Cluster B $^{2}$ & $0.49 * * *$ & 0.15 & -0.04 & 0.15 & $0.41^{* * *}$ \\
${\text { Cluster } \mathrm{C}^{3}}$ & 0.10 & $0.51^{* * *}$ & 0.01 & 0.11 & 0.04 \\
\hline
\end{tabular}

I. Partial correlations controlling for cluster $B$ and $C$ scores.

2. Partial correlations controlling for cluster $A$ and $C$ scores.

3. Partial correlations controlling for cluster $A$ and $B$ scores.

$* P<0.05, * * P<0.01, * * * P<0.001$. and which probably reflect a mixture of their own dynamics, 'pulls' from the clinician and the interaction of patient and therapist actions and dynamics. These patterns occur across a range of therapeutic orientations and technical strategies, and do not appear to reflect clinicians' theoretical preconceptions. This finding is consistent with results of several recent studies using clinician-report methods to assess personality and psychopathology, which find that clinicians' descriptions of patients tend not to reflect their theoretical beliefs or diagnostic prototypes.

\section{Relationship of PRQ dimensions to attachment styles and personality pathology}

A striking - and somewhat unexpected finding is the extent to which these dimensions map on to adult attachment styles identified using the Adult Attachment Interview (AAI; Main et al, 1985). The AAI is a narrative-based interview that codes attachment status based on the extent to which the person can speak freely and coherently about relationships with present and past attachment figures. Although clearly not all therapy relationships are attachment relationships (which are characterised by features such as desires for proximity to, and discomfort with physical or psychological distance from, an attachment figure), the findings support the view that the therapy relationship, as an intimate, emotionally charged, asymmetrical and typically nurturant relationship, is likely to activate many attachment-related patterns of thought and feeling and affect regulation, motivation, conflict and so forth (see Fonagy et al, 1996; Seligman, 2000). To the extent that this is the case, examination of these patterns in vivo can provide insight into some of the patient's central dynamics in close interpersonal relationships; and, by extension, as argued for a century by psychodynamic theorists (and more recently by others; e.g. Safran \& Muran, 2000; Ryle, 2001), changes in patterns of responding in the therapy relationship may generate changes in extratherapeutic relationships and their intrapsychic concomitants.

Although all patients have their own idiosyncratic ways of responding, the latent dimensions that emerged describe a range of ways patients respond not only to an intimate relationship but to the inherent 
Table 3 Transference items (Z-scored) most and least descriptive of patients meeting DSM-IV criteria for narcissistic personality disorder $(n=13)$

Transference item

Z mean (s.d.)

\section{Most descriptive}

Needs excessive admiration from the therapist

$1.85(1.30)$

Behaves in ways that seem entitled (e.g. wants special favours, a lower fee than is

$1.66(1.56)$

warranted by his/her income)

Vacillates between idealising and devaluing the therapist

$1.51(1.51)$

Is off-putting

Requires or demands excessive contact, love, etc., from the therapist

I.39 (1.44)

$1.37(1.56)$

Expresses wish that the therapist could be his/her parent

Is boring

Plays the therapist off against another person (e.g. a parent, spouse or other

$1.32(1.62)$

$1.30(1.04)$

$1.26(1.68)$

therapist)

Needs to be special to the therapist; wants to be more important than the

I.2I (1.09)

therapist's other patients

Is sadistic toward the therapist (e.g. enjoys making the therapist squirm)

Feels criticised by the therapist

$1.21(2.22)$

$1.18(1.25)$

I.16 (1.15)

Assumes that the therapist shares his/her point of view, beliefs, values, etc.,

even where this is unlikely

Feels critical of the therapist

Elicits sadism, sarcasm or other subtle or overt aggressive responses from

the therapist

Imagines $s /$ he and the therapist are much more similar than they really are;

$1.10(1.33)$

seems to want to be 'twins' with the therapist

Feels mistreated or abused by the therapist

Is consumed by the therapy; is preoccupied with the therapist, therapy, etc.

$1.08(1.94)$

1.06 (1.58)

$1.05(1.31)$

Is competitive with the therapist

$-0.67(0.82)$

Is empathic toward the therapist's feelings

$-0.51(0.94)$

Elicits warm feelings from the therapist

$-0.29(0.92)$

Is able to talk openly about difficult material

$-0.18(0.91)$

Is attuned to the verbal and non-verbal meanings of the therapist's communications,

is adept at reading subtle social cues

Works hard in therapy

$-0.17(0.77)$

Has trouble talking about own successes, achievements or pride with the therapist

Is afraid of contradicting or disagreeing with the therapist; has trouble asserting

$-0.11(0.80)$

$-0.10(0.85)$

own needs or viewpoint

Is indifferent to the therapist; expresses little feeling towards the therapist, either

$-0.04(0.91)$ 'one foot out of the door' or hold the therapist emotionally at bay. Still other patients (not well characterised by the attachment literature, given its origins in infant research) may sexualise the therapy relationship to try to establish some form of connection, repeat or try to work through a past trauma, or fear that the therapist will sexualise it.

One of the dimensions that emerged (secure/engaged) seems to describe not only a style of attachment in which the patient feels comfortable, secure and able to talk freely and with affect about emotionally significant experiences, but also a dimension frequently described as the 'working alliance' (Greenson, 1965; Bordin, 1979), which has been shown empirically to be one of the best predictors of treatment outcome in psychotherapy (Horvath \& Symonds, 1991; Martin et al, 2000). That items reflecting a positive working alliance and items resembling secure attachment loaded on a single factor probably reflects the fact that working alliance and transference involve similar cognitive processes involving activation of representations, affects and affect regulation strategies based on the match between the current situation or relationship and prototypes from the past (Westen \& Gabbard, 2002). Thus, although the distinction between working alliance and transference may be heuristically useful, the patient's response in both cases is based on a combination of prior expectations and current situational primes.

An additional finding is that patterns of transference appear to be systematically related to enduring personality styles, supporting a fundamental hypothesis first advanced by Freud decades ago, that the patterns emerging in the therapeutic relationship are not arbitrary. To what extent they mirror childhood relationships cannot be determined from these data, but they clearly reflect patterns seen elsewhere in patients' lives that can be crucial to address. Of particular note is that the empirical portrait of transference patterns in patients with narcissistic personality disorder strongly resembles clinical descriptions of narcissistic transferences. This is especially striking given that most of the patients diagnosed with narcissistic personality disorder were not described by clinicians with a psychodynamic orientation, and the same portrait emerged when we did not include descriptions by dynamically oriented clinicians. 


\section{Limitations}

This study has three primary limitations. The first is the exclusive reliance on a single informant (the treating clinician), a design flaw shared with most studies of psychopathology, which typically rely on patients rather than clinicians as the sole informant. The failure to identify systematic biases associated with theoretical orientation renders explanations based on clinician bias unlikely; however, future research using this measure should clearly assess its validity and correlates using data provided by other observers. Some of the most important research in this area has involved observer ratings of interaction patterns in psychotherapy, which do not rely on clinicians' accurate reporting of events in the consulting room. The most sustained efforts along these lines have used Luborsky's Core Conflictual Relationship Theme method (Luborsky \& Crits-Christoph, 1990), which is designed to capture the patient's wishes, the expected or actual response from the clinician, and the patient's reactions to that response. This method has numerous advantages, most importantly objectivity (an outside observer) and reliability of measurement (the use of multiple observers to obtain interrater reliability). Its primary difficulty is that it is labourintensive and requires extensive training to use reliably.

The second limitation is response rate. Although this is a genuine concern, three factors limit the likelihood that the results reflect response rate biases. First and foremost, it is hard to imagine a response rate hypothesis that could explain the pattern of results. By virtue of their willingness to donate $3-4 \mathrm{~h}$ of their time for a modest honorarium, clinicians who participated in the study might have differed from their colleagues on untold variables, but it is difficult to see how any of these variables could have produced the obtained findings. Second, clinicians who agreed to participate were unaware that transference was one of the constructs we intended to study. Third, psychologists responded at more than twice the rate of psychiatrists, yet the two sets of informants provided similar data, suggesting that neither training nor response rate was responsible for the findings.

A third potential objection is sample size, given the possibility of some instability of factor structure with a 2:1 ratio of cases to items. However, recent thinking about factor analysis, based on data from Monte Carlo simulations and other studies, suggests that factor solutions stabilise with far fewer cases than previously believed (typically by 100 cases) as long as the factors are well marked by a sufficient number of items with loadings above 0.40 or 0.50 (as they were here), and that conventional case-to-item ratios do not take into consideration a range of variables that qualifies them in one direction or the other (see Fabregar et al, 1999; Russell, 2002). The next step in this research is a replication study with a larger sample, using confirmatory factor analysis, observer ratings of tape-recorded sessions and external ratings of variables such as personality disorder diagnosis and treatment outcome independent of the clinicians' reports.

\section{Implications}

Transference phenomena are neither mysterious nor unmeasurable. They reflect the tendency of the brain to map current on to past experience and to craft responses that represent a combination of automatic activation of procedures and mental representations from the past, integration of current with past data and experience to generate responses that reflect the coactivation of old and new neural networks, and creative problem-solving activities. The PRQ represents an effort to develop a relatively easy-to-administer measure designed for expert clinical observers (clinicians or clinically trained coders listening to audiotapes or videotapes) that reflects shared clinical wisdom in its item content and statistical 'wisdom' in its factor structure. The development of clinician-report measures such as this may be useful not only for research but for practice, allowing clinicians to rate patients on normed instruments with known correlates, and hence to turn clinical phenomena such as transference responses into quantifiable dimensions that can be examined and used as indices of clinically meaningful change.

\section{ACKNOWLEDGEMENTS}

Preparation of this paper was supported by grants from the National Institute of Mental Health and the Fund for Psychoanalytic Research of the American Psychoanalytic Association.

\section{REFERENCES}

American Psychiatric Association (1987) Diagnostic and Statistical Manual of Mental Disorders (3rd edn, revised) (DSM-IIII-R). Washington, DC: APA.

American Psychiatric Association (1994) Diagnostic and Statistical Manual of Mental Disorders (4th edn) (DSM-IV). Washington, DC: APA.

Audin, K., Mellor-Clark, J., Barkham, M., et al (200I) Practice research networks for effective psychological therapy. Journal of Mental Health (UK), 10, 24I-25I.

Bordin, E. S. (1979) The generalizability of the psychoanalytic concept of the working alliance. Psychotherapy: Theory, Research and Practice, 16, 252-260.

Curtis, J.T., Silberschatz, G., Sampson, H., et al (1994) The Plan Formulation Method. Psychotherapy Research, 4, 197-207.

Fabregar, L. R., Wegener, D. T., MacCallum, R. C. et al (1999) Evaluating the use of exploratory factor analysis in psychological research. Psychological Methods, 4. 272-299.

Fonagy, P., Leigh, T., Steele, M., et al (1996) The relation of attachment status, psychiatric classification, and response to psychotherapy. Journal of Consulting and Clinical Psychology, 64, 22-31.

Freud, S. (1912) The dynamics of transference. Reprinted (1953-1974) in the Standard Edition of the Complete Psychological Works of Sigmund Freud (trans. and ed. J. Strachey), vol. 12, pp. 97-108. London: Hogarth Press.

Freud, S. (1917) Introductory lectures on psychoanalysis: Part III. General theory of the neuroses. Reprinted (1953-1974) in the Standard Edition of the Complete Psychological Works of Sigmund Freud (trans. and ed. J. Strachey), vol. 16, pp. 243-436. London: Hogarth Press.

Greenson, R. R. (1965) The working alliance and the transference neurosis. Psychoanalytic Quarterly, 34, 155-179.

Hilsenroth, M. J., Ackerman, S. J., Blagys, M. D. et al (2000) Reliability and validity of DSM-IV axis V. American Journal of Psychiatry, 157, 1858-1863.

Horn, L. (1965) A rationale and test for the number of factors in factor analysis. Psychometrika, 30, 179-185.

Horvath, A. O. \& Symonds, B. (1991) Relation between working alliance and outcome in psychotherapy: a meta-analysis. Journal of Counseling Psychology, 38, 139-149.

Kernberg, O. (1975) Borderline Conditions and Pathological Narcissism. Northvale, NJ: Jason Aronson.

Kohut, H. (1968) The psychoanalytic treatment of narcissistic personality disorders: outline of a systematic approach. In Psychoanalytic Study of the Child, pp. 86-113. New Haven, CT:Yale University Press.

Luborsky, L. \& Crits-Christoph, P. (1990)

Understanding Transference: The Core Conflictual Relationship Theme Method. New York: Basic Books.

Main, M., Kaplan, N. \& Cassidy, J. (1985) Security in infancy, childhood, and adulthood: a move to the level of representation. Monographs of the Society for Research in Child Development, 50, 66-104.

Margison, F. R., McGrath, G., Barkham, M., et a (2000) Measurement and psychotherapy: evidencebased practice and practice-based evidence. British Journal of Psychiatry, 177, 123-130.

Martin, D. J., Garske, J. P. \& Davis, M. K. (2000) Relation of the therapeutic alliance with outcome and 
other variables: a meta-analytic review. Journal of Consulting and Clinical Psychology, 68, 438-450.

Nakash-Eisikovits, O., Dutra, L. \& Westen, D. (2002) Relationship between attachment patterns and personality pathology in adolescents. Journal of the American Academy of Child and Adolescent Psychiatry, 4I IIII-II23.

O'Connor, B. P. (2000) SPSS and SAS programs for determining the number of components using parallel analysis and Velicer's MAP test. Behavior Research Methods, Instruments, and Computers, 32, 396-402.

Russ, E., Heim, A. \& Westen, D. (2003) Parental bonding and personality pathology assessed by clinician report. Journal of Personality Disorders, 17, 522-536.

Russell, D. W. (2002) In search of underlying dimensions: the use (and abuse) of factor analysis. Personality and Social Psychology Bulletin, 28, 1629-1646.

Ryle, A. (200I) Cognitive analytic therapy. In Handbook of Personality Disorders: Theory, Research, and Treatment (ed.W. Livesley), pp. 400-413. New York: Guilford.

Safran, J. D. \& Muran, J. C. (2000) Negotiating the Therapeutic Alliance: A Relational Treatment Guide. New York: Guilford.

Sandler, J. (1976) Countertransference and roleresponsiveness. International Review of Psycho-Analysis, $\mathbf{3}$, 43-47.

Seligman, S. (2000) Clinical implications of current attachment theory. Journal of the American Psychoanalytic Association, 48, II89-1195.

Shedler, J. \& Westen, D. (2004) Dimensions of personality pathology: an alternative to the Five Factor Model. American Journal of Psychiatry, 16I, 1743-1754.

Thompson-Brenner, H. \& Westen, D. (2005) A naturalistic study of psychotherapy for bulimia nervosa. Part I: Comorbidity and therapeutic outcome. Journal of Nervous and Mental Disease, in press.

Wachtel, P. (1997) Psychoanalysis, Behavior Therapy, and the Relational World.Washington, DC: American Psychological Association Press.

Westen, D. (2000) Psychotherapy Relationship Questionnaire (PRQ) Manual. Available at http: // www.psychsystems.Net/lab

Westen, D. \& Gabbard, G. O. (2002) Developments in cognitive neuroscience: II. Implications for theories of transference. Journal of the American Psychoanalytic Association, 50, 99-134.

Westen, D. \& Muderrisoglu, S. (2003) Reliability and validity of personality disorder assessment using a systematic clinical interview: evaluating an alternative to

\section{CLINICAL IMPLICATIONS}

- Transference phenomena are not only measurable but show predictable correlations with personality diagnoses, such as narcissistic personality disorder.

- Many of the primary transference patterns empirically identified in this study through factor analysis appear to converge with research on adult attachment patterns, and describe ways of dealing with intimacy, affect and vulnerability in an emotionally significant relationship.

- The Psychotherapy Relationship Questionnaire may be useful clinically in understanding patients' transference responses in a rigorous but clinically nuanced way.

\section{LIMITATIONS}

- The data reflect the observations of a single informant and need to be replicated with multiple observers.

- Response rates by clinicians were relatively low, reflecting a large time commitment for a small honorarium.

- The sample size was relatively small for factor-analytic research; future research should use confirmatory factor-analytic procedures with a large sample.

REBEKAH BRADLEY, PhD, AMY KEGLEY HEIM, PhD, DREW WESTEN, PhD, Departments of Psychology and Psychiatry and Behavioral Sciences, Emory University, Atlanta, Georgia, USA

Correspondence: Professor Drew Westen, Department of Psychiatry and Behavioral Sciences, Emory University, Atlanta,GA 30322,USA. E-mail: dwesten@emory.edu

(First received 10 February 2004, final revision 23 September 2004, accepted 30 September 2004)

structured interviews. Journal of Personality Disorders, $\mathbf{1 7}$ 350-368.

Westen, D. \& Shedler, J. (1999) Revising and assessing Axis II, Part I: developing a clinically and empirically valid assessment method. American journal of Psychiatry, 156, $258-272$
Westen, D. \& Weinberger, J. (2004) When clinical description becomes statistical prediction. American Psychologist, 59, 595-613.

Westen, D., Shedler, J., Durrett, C., et al (2003) Personality diagnosis in adolescence: DSM-IV axis II diagnoses and an empirically derived alternative. American Journal of Psychiatry, 160, 952-966. 